\title{
The Socioeconomic Burden of Obesity
}

\author{
Jakob Kjellberg ${ }^{a} \quad$ Arendse Tange Larsen $^{b} \quad$ Rikke Ibsen $^{c}$ Betina Højgaard ${ }^{a}$ \\ a Danish Institute for Local and Regional Government Research, Copenhagen, Denmark; \\ b University of Copenhagen, Copenhagen, Denmark; ci2minds; Aarhus, Denmark
}

\section{Keywords}

BMI $\cdot$ Body mass index $\cdot$ Economics $\cdot$ Healthcare costs $\cdot$ Obesity

\begin{abstract}
Objective: To evaluate the socioeconomic impact of obesity by estimating the direct and indirect costs associated with obesity in Denmark, based on individual level data. Methods: Costs were assessed for different BMI groups, and the relative risks for change in direct and indirect costs per BMI point above 30 were estimated. A fourth analysis estimated the odds ratio for comorbidities per BMI point above 30. Individual data on income, social transfer payments, healthcare costs and diagnoses were retrieved from national registries. Results: One BMI point above 30 was associated with a $2 \%$ decrease in income, a $3 \%$ increase in social transfer payments, and a $4 \%$ increase in healthcare costs. In absolute numbers, income contributed to most of the total economic burden. One BMI point above 30 was also associated with increased comorbidity, which explains the increase in both direct and indirect costs. Conclusion: Obesity is associated with increased comorbidity, giving rise to an increase in both direct and indirect costs. Especially income is affected, which emphasizes the importance of including both measures when evaluating the total socioeconomic burden of obesity. Our findings draw attention to the potential for saving public resources and preventing loss of income by preventing obesity.

(C) 2017 The Author(s)

Published by S. Karger GmbH, Freiburg
\end{abstract}

\section{Introduction}

Obesity is a growing problem in most countries, Denmark being no exception. WHO defines obesity as BMI $>30 \mathrm{~kg} / \mathrm{m}^{2}$ [1], which applied to $14.1 \%$ of all Danish adults in 2013 [2]. Obesity is associated with increased risk of morbidity [3-7] as well as excess mortality [5-9] because of the comorbidities associated with obesity, which underlines the cause for concern. However, obesity does not only have adverse implications for health but also for 
socioeconomics. Previous studies have found that obesity induces higher healthcare costs due to treatment of obesity-related diseases [10-25]. In a prospective cohort study Andreyeva et al. [26] found that BMI $30-35 \mathrm{~kg} / \mathrm{m}^{2}$, BMI $30-40 \mathrm{~kg} / \mathrm{m}^{2}$ and BMI $>40 \mathrm{~kg} / \mathrm{m}^{2}$ was associated with $\sim 25 \%, \sim 50 \%$ and $\sim 100 \%$ greater healthcare expenditures than normal weight, respectively. Likewise, Finkelstein et al. [27] have found that BMI $>30 \mathrm{~kg} / \mathrm{m}^{2}$ was associated with an average increase of $37.4 \%$ in annual healthcare expenditures.

Although the association between obesity and healthcare costs is fairly well covered, the relationship between obesity and other costs due to, for instance, productivity losses is less explored. Previous studies have found obesity to be associated with absenteeism and unemployment [28-33]. Loss of income is of relevance for the individual but may also have a substantial socioeconomic impact. Because of the increasing prevalence of obesity and its potential impact on society, it is important to provide information on direct healthcare costs and other obesity-related costs of socioeconomic importance as well. DiBonaventura et al. [34] found a decrease in work productivity with increasing BMI. They found that health problems among obese individuals resulted in an overall work impairment of $20 \%$. Moreover, a lower income among people with BMI $>30 \mathrm{~kg} / \mathrm{m}^{2}$ was identified. In addition, in their review Trogdon et al. [32] found that obese workers miss more workdays than non-obese workers because of illness or disability. However, most of these results were based on self-reporting, company reporting, and calculations made from average income and work time measurements. In Denmark, it is possible to retrieve information on, for instance, health, medication, employment status and income level from national registries. This information is linked to a unique identification number (Central Personal Registration (CPR) number) assigned for all persons residing in Denmark by the Danish Civil Registration System. This makes it possible to identify obese subjects and link them individually with information for calculating both direct and indirect costs.

To our knowledge, the opportunity to estimate both direct and indirect costs associated with obesity based on the unique Danish registration system has not previously been seized. The current study aims to contribute to the exploration of the socioeconomic burden of obesity by adding real-world data-based analyses of the impact of obesity on social transfer payments and income among obese adults in Denmark.

\section{Material and Methods}

An analysis of costs in different BMI groups and three regression analyses were performed. The first and second regression analyses estimate the relative risk (RR) for change in social transfer payments/income and healthcare costs, respectively, per BMI point above 30. The third regression analysis estimates the odds ratio (OR) for comorbidities per BMI point above 30 .

\section{Population and Primary Measure}

The population was extracted as a representative sample of a pooled population comprised of respondents from The Danish National Health Profile 2010 and 2013 with BMI > $30 \mathrm{~kg} / \mathrm{m}^{2}$. If a respondent from 2010 recurred in 2013, the person was excluded from the 2013 sample. BMI was calculated $\left(\mathrm{kg} / \mathrm{m}^{2}\right) \mathrm{using}$ self-reported height and weight from the Danish National Health Profile. The Danish National Health Profile is a national study on the Danish population's health including health behavior, well-being, and mortality. The study is based on questionnaire surveys and data from the national registries, and it represents Danish citizens over 16 years of age. About 300,000 questionnaires were sent out in both 2010 and 2013, and the response rate was about $55 \%[35,36]$.

BMI was grouped according to WHO's classifications of obesity: BMI 30-34.9 kg/m² (obese class I), BMI $35-39.9 \mathrm{~kg} / \mathrm{m}^{2}$ (obese class II) and BMI $>40 \mathrm{~kg} / \mathrm{m}^{2}$ (obese class III). We excluded outliers defined as individuals with BMI $>55 \mathrm{~kg} / \mathrm{m}^{2}$. Furthermore, we only included individuals in the labor force (18-64 years) in the analysis of social transfer payments and income. As a result, 44,904 individuals with BMI $30-55 \mathrm{~kg} / \mathrm{m}^{2}$ 
were included in the analysis of costs in different BMI groups and in the regression analyses of healthcare costs and comorbidity. 32,923 individuals with BMI $30-55 \mathrm{~kg} / \mathrm{m}^{2}$ were included in the analysis of social transfer payments and income.

\section{Outcome Variables}

Outcome variables included income, social transfer payments, healthcare costs, and comorbidities. Income comprised annual earnings, profit from own business, private pension, and other types of income not derived from state coffers, but including state education grants, which could not be separated from data. Social transfer payments were retrieved as total costs and categorized into different types of payment in the regression analysis: social security, disability pension, sick pay, early retirement benefit, unemployment fund, housing benefit, and child benefit. Housing benefit is a subsidy to one's rent that can be assigned to tenants or to beneficiaries of invalidity pension, disability pension, or state pension. Child benefit is assigned to citizens chargeable with tax and in custody of one or more children. This benefit is disbursed automatically and requires no application. Healthcare costs were also retrieved as total costs and categorized into seven types of healthcare in the regression analysis: somatic inpatient services, somatic outpatient services, somatic emergency department, primary health sector, psychiatric inpatient services, psychiatric outpatient services, and drug costs. Comorbidities were extracted as primary and secondary diagnoses and categorized into main disease groups according to the International Statistical Classification of Diseases and Related Health Problems 10th Revision (ICD-10) chapters 1-21.

Data on inpatient and outpatient services were retrieved from the National Patient Registry, which includes data on all patient contacts, including diagnoses as well as diagnostic and treatment procedures. The database uses international classification systems, for instance, the ICD-10. Data were linked with the Danish Case Mix System (Diagnosis-Related Groups) in order to estimate the associated costs. The costs of healthcare use in the primary sector were obtained from the National Health Insurance Service Register, and data on drug use and costs were extracted from the Danish Medicines Agency. Costs of drugs were calculated by multiplying the retail price of each drug with the prescribed quantity. Information on social transfer payments, income and home help was also derived from national registries from Statistics Denmark.

All costs in the analysis of costs in different BMI groups were adjusted to 2014 price levels and converted to EUR (1 EUR = 0.94 USD).

\section{Covariates}

We adjusted for baseline characteristics retrieved from the Civil Registration System and Statistics Denmark: sex (male or female), age (in categories 18-29 years, 30-39 years, 40-49 years, 50-59 years, and $>60$ years), marital status (married/civil partnership or single), education (primary school, high school, vocational education, short education, medium education, higher education, or unknown), and municipality.

\section{Analytical Model}

Because the distributions of healthcare costs, social transfer payments, and income are left skewed and include a large proportion with costs equaling 0 , a gamma-distributed two-step model was applied. Costs have thus been estimated using a one-model generalized linear model with link = log and gamma distribution [37]. A Conditional Logit Model was used for estimating OR and significance for comorbidity per added BMI point above 30. Analyses were performed using SAS 9.1.3 (Cary, NC, USA), and the significance level was set to 0.05.

\section{Ethics}

The current study was approved by the Danish Data Protection Agency. In Denmark, only studies involving intervention or biological material require ethical approval under the Committee Act. The current study involved register data only, for which reason no ethical approval was necessary.

\section{Results}

\section{Population Characteristics}

Table 1 shows baseline characteristics of the population in all analyses. The analysis of social transfer payments and income included 32,923 individuals, while the analyses of healthcare costs and comorbidity included 44,904 individuals. The assessment of costs in 
Kjellberg et al.: The Socioeconomic Burden of Obesity

Table 1. Baseline characteristics of the two populations

\begin{tabular}{lll}
\hline & $\begin{array}{l}\text { Social transfer payments and } \\
\text { income }\end{array}$ & $\begin{array}{l}\text { Healthcare costs and } \\
\text { comorbidities }\end{array}$ \\
\hline $\begin{array}{l}\text { Population size, n } \\
\text { Age, years }\end{array}$ & 32,923 & 44,904 \\
Distribution, n (\%) & $47.2 \pm 11.8$ & $53.3 \pm 15.3$ \\
$\quad<18$ years & - & $269(0.6 \%)$ \\
18-29 years & $3,114(9.5 \%)$ & $3,114(6.9 \%)$ \\
30-39 years & $5,314(16.1 \%)$ & $5,314(11.8 \%)$ \\
40-49 years & $9,024(27.4 \%)$ & $9,024(20.1 \%)$ \\
50-59 years & $9,681(29.4 \%)$ & $9,681(21.6 \%)$ \\
60-64 years & $5,790(12.9 \%)$ & $5,790(17.6 \%)$ \\
65+ years & - & $11,712(26.1 \%)$ \\
Sex ,n (\%) & $15,791(48.0 \%)$ & $21,995(49.0 \%)$ \\
$\quad$ Male & $17,132(52.0 \%)$ & $22,909(51.0 \%)$ \\
Female & & \\
Marital status, n (\%) & $24,754(75.2 \%)$ & $32,479(72.3 \%)$ \\
$\quad$ Married/civil partnership & $8,169(24.8 \%)$ & $12,425(27.7 \%)$ \\
Single & & \\
Education, n (\%) & $8,660(26.3 \%)$ & $14,441(32.2 \%)$ \\
$\quad$ Primary school & $1,864(5.7 \%)$ & $1,954(4.4 \%)$ \\
High school & $14,156(43.0 \%)$ & $18,399(41.0 \%)$ \\
Vocational education & $1,599(4.9 \%)$ & $1,866(4.2 \%)$ \\
Short education & $4,769(14.5 \%)$ & $5,873(13.1 \%)$ \\
Medium education & $1,341(4.1 \%)$ & $1,594(3.5 \%)$ \\
Long education & $534(1.6 \%)$ & $777(1.7 \%)$ \\
Education unknown & & \\
\hline
\end{tabular}

different BMI groups is based on the same population as the regression analyses of healthcare costs and comorbidities. The mean age in the two populations was 47.2 or 53.3 years, and females were slightly over-represented in both populations $(52.0 \%$ or $51.0 \%)$. The majority of both populations were married or in civil partnerships (75.2\% or $72.3 \%)$, and vocational education was the most common education level (43.0\% or $41.0 \%)$.

\section{Costs and Income for Different BMI Groups}

The mean annual income, social transfer payments, healthcare costs, and home help costs in obesity class I, II, and III are presented in table 2 . The results indicate that among obese individuals increased BMI is associated with increased social transfer payments, home help costs, and health costs as well as with decreased income. Especially income is affected, showing the greatest change in absolute numbers with higher BMI.

\section{Income, Social Transfer Payments, and Healthcare Costs}

As seen in table 3, income was negatively influenced by increased BMI, as one BMI point above 30 was associated with a $2 \%$ decrease in income. Furthermore, the total costs of social transfer payments increased with a rate of $3 \%$ per BMI point. Especially costs of social security and disability pension increased with a rate of $5 \%$ and $6 \%$, respectively. In contrast, costs of early retirement benefit and child benefits were both negatively affected, decreasing with a rate of $3 \%$ and $1 \%$, respectively. All estimates were significant and adjusted for age, sex, municipality, and education.

One BMI point above 30 was associated with a $4 \%$ increase in average total healthcare costs ranging between $1 \%$ and $10 \%$, when looking at the individual costs (table 3 ). An increase of one BMI point was associated with a $5 \%$ increase in drug costs and a $10 \%$ increase in 
Table 2. Mean annual income, social transfer payments, healthcare costs and home help costs

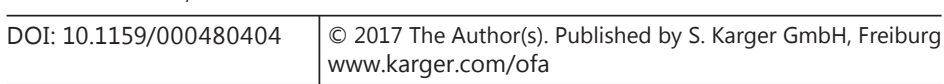

Kjellberg et al.: The Socioeconomic Burden of Obesity

\begin{tabular}{llll}
\hline & Class I & Class II & Class III \\
& $\mathrm{N}=33,735$ & $\mathrm{~N}=8,219$ & $\mathrm{~N}=2,950$ \\
\hline $\begin{array}{l}\text { Income, EUR } \\
\text { Total social transfer payments, } \\
\quad \text { EUR }\end{array}$ & 31,379 & 28,684 & 25,422 \\
$\begin{array}{l}\text { Total healthcare costs, EUR } \\
\text { Total home help costs, EUR }\end{array}$ & 9,039 & 9,889 & 11,039 \\
& 214 & 3,577 & 4,672 \\
\end{tabular}

Table 3. RR for income, social transfer payments and health care costs per BMI point above 30

\begin{tabular}{lll}
\hline & RR $(95 \% \mathrm{CI})$ & p values \\
\hline Income & $0.98(0.98 ; 0.99)$ & $<0.001$ \\
Total social transfer payments & $1.03(1.02 ; 1.03)$ & $<0.001$ \\
Social security & $1.05(1.05 ; 1.06)$ & $<0.001$ \\
Disability pension & $1.06(1.06 ; 1.06)$ & $<0.001$ \\
Sick pay & $1.03(1.03 ; 1.03)$ & $<0.001$ \\
Early retirement benefit & $0.97(0.96 ; 0.97)$ & $<0.001$ \\
Unemployment fund & $1.03(1.03 ; 1.03)$ & $<0.001$ \\
Housing benefit & $1.02(1.01 ; 1.02)$ & $<0.001$ \\
Child benefit & $0.99(0.99 ; 0.99)$ & $<0.001$ \\
Total healthcare costs* & $1.04(1.03 ; 1.04)$ & $<0.001$ \\
Somatic inpatient services & $1.04(1.04 ; 1.04)$ & $<0.001$ \\
Somatic outpatient services & $1.03(1.02 ; 1.03)$ & $<0.001$ \\
Somatic emergency department & $1.01(1.01 ; 1.02)$ & $<0.001$ \\
Primary healthcare & $1.02(1.02 ; 1.02)$ & $<0.001$ \\
Psychiatric inpatient services & $1.10(1.09 ; 1.10)$ & $<0.001$ \\
Psychiatric outpatient services & $1.04(1.04 ; 1.05)$ & $<0.001$ \\
Drug costs & $1.05(1.05 ; 1.06)$ & $<0.001$ \\
\hline
\end{tabular}

*Home help did not converge in the model and was therefore omitted.

psychiatric inpatient visits. The somatic emergency department was affected with a $1 \%$ increase. All estimates were significant and adjusted for age, sex, municipality, and education.

\section{Comorbidities}

We found that one BMI point above 30 was associated with a general risk increase for morbidity (table 4). However, only five estimates were significant: One BMI point above 30 was associated with $12 \%$ greater odds for code 3 : 'diseases of the blood etc.', $6 \%$ greater odds for code 4: 'endocrine, nutritional and metabolic diseases', $4 \%$ greater odds for codes 9 and 6: 'diseases of the circulatory system' and 'diseases of the nervous system', respectively, and finally 3\% greater odds for code 19: 'injury, poisoning etc'. The two most common significant disease groups were endocrine, nutritional, and metabolic diseases as well as diseases of the circulatory system. All estimates were adjusted for age, sex, municipality, and education.

\section{Discussion}

To our knowledge, this is the first register-based study evaluating the socioeconomic impact of obesity by estimating the direct and indirect costs associated with increased BMI among individuals with BMI $>30 \mathrm{~kg} / \mathrm{m}^{2}$. Thus, we look at the total burden of increased BMI 
Kjellberg et al.: The Socioeconomic Burden of Obesity

Table 4. OR for comorbidities among people with BMI $>30 \mathrm{~kg} / \mathrm{m}^{2}$

\begin{tabular}{|c|c|c|c|c|c|c|}
\hline Ch. & Section & Disease group & $\begin{array}{l}\text { BMI } 30-55 \mathrm{~kg} / \mathrm{m}^{2} \\
\mathrm{~N}=44.904\end{array}$ & $\%$ & OR $(95 \% \mathrm{CI})$ & $\mathrm{p}$ values \\
\hline 1 & A00-B99 & $\begin{array}{l}\text { certain infectious and parasitic } \\
\text { diseases }\end{array}$ & 533 & 1.2 & $1.04(0.96 ; 1.11)$ & 0.337 \\
\hline 2 & C00-D48 & neoplasms & 2,250 & 5.0 & $0.98(0.95 ; 1.02)$ & 0.311 \\
\hline 3 & D50-D89 & $\begin{array}{l}\text { diseases of the blood and blood- } \\
\text { forming organs etc. }\end{array}$ & 388 & 0.9 & $1.12(1.02 ; 1.23)$ & 0.014 \\
\hline 4 & E00-E90 & $\begin{array}{l}\text { endocrine, nutritional and metabolic } \\
\text { diseases }\end{array}$ & 4,205 & 9.4 & $1.06(1.03 ; 1.09)$ & 0.000 \\
\hline 5 & F00-F99 & mental and behavioral disorders & 464 & 1.0 & $1.01(0.95 ; 1.08)$ & 0.751 \\
\hline 6 & G00-G99 & diseases of the nervous system & 1,825 & 4.1 & $1.04(1.01 ; 1.08)$ & 0.023 \\
\hline 7 & $\mathrm{H} 00-\mathrm{H} 59$ & diseases of the eye and adnexa & 1,106 & 2.5 & $1.02(0.97 ; 1.07)$ & 0.468 \\
\hline 8 & H60-H95 & $\begin{array}{l}\text { diseases of the ear and mastoid } \\
\text { process }\end{array}$ & 795 & 1.8 & $1.03(0.98 ; 1.09)$ & 0.229 \\
\hline 9 & I00-I99 & diseases of the circulatory system & 4,626 & 10.3 & $1.04(1.02 ; 1.07)$ & 0.001 \\
\hline 10 & J00-J99 & diseases of the respiratory system & 1,389 & 3.1 & $1.04(1.00 ; 1.08)$ & 0.074 \\
\hline 11 & K00-K93 & diseases of the digestive system & 2,521 & 5.6 & $1.02(0.99 ; 1.05)$ & 0.178 \\
\hline 12 & L00-L99 & $\begin{array}{l}\text { diseases of the skin and subcutaneous } \\
\text { tissue }\end{array}$ & 777 & 1.7 & $1.05(0.99 ; 1.11)$ & 0.106 \\
\hline 13 & M00-M99 & $\begin{array}{l}\text { diseases of the musculoskeletal system } \\
\text { and connective tissue }\end{array}$ & 4,795 & 10.7 & $1.01(0.99 ; 1.04)$ & 0.293 \\
\hline 14 & N00-N99 & diseases of the genitourinary system & 2,247 & 5.0 & $1.00(0.97 ; 1.03)$ & 0.979 \\
\hline 15 & 000-099 & $\begin{array}{l}\text { pregnancy, childbirth and the } \\
\text { puerperium }\end{array}$ & 622 & 1.4 & $0.94(0.87 ; 1.03)$ & 0.172 \\
\hline 16 & P00-P96 & $\begin{array}{l}\text { certain conditions originating in the } \\
\text { perinatal period }\end{array}$ & 4 & 0.0 & - & - \\
\hline 17 & Q00-Q99 & $\begin{array}{l}\text { Congenital malformations, } \\
\text { deformations and chromosomal } \\
\text { abnormalities }\end{array}$ & 166 & 0.4 & $1.00(0.88 ; 1.13)$ & 0.950 \\
\hline 18 & R00-R99 & $\begin{array}{l}\text { symptoms, signs and abnormal clinical } \\
\text { and laboratory findings, not elsewhere } \\
\text { classified }\end{array}$ & 3,423 & 7.6 & $1.03(1.00 ; 1.06)$ & 0.056 \\
\hline 19 & S00-T98 & $\begin{array}{l}\text { injury, poisoning and certain other } \\
\text { consequences of external causes }\end{array}$ & 3,992 & 8.9 & $1.03(1.00 ; 1.05)$ & 0.048 \\
\hline 20 & X60-Y09 & $\begin{array}{l}\text { external causes of morbidity and } \\
\text { mortality }\end{array}$ & 5 & 0.0 & - & - \\
\hline 21 & Z00-Z99 & $\begin{array}{l}\text { factors influencing health status and } \\
\text { contact with health services }\end{array}$ & 18,310 & 4.8 & $1.01(0.99 ; 1.02)$ & 0.431 \\
\hline
\end{tabular}

Significant results are indicated in italics.

among obese individuals. This was possible because all Danes have a unique identification number, which enables individual linkage between national registries. We identified a $2 \%$ decrease in income, a 3\% increase in social transfer payments, and a 4\% increase in healthcare costs per BMI point above 30 .

Previous studies have mainly focused on healthcare costs associated with obesity and to a lesser extent on indirect costs and costs of social transfer payments. The current study contributes information on precisely these measures. DiBonaventura et al. [34] conducted a study in which they identified an association between increased BMI and decreased work productivity, indicating that public expenses and personal income might also be affected by obesity. Our findings support this consideration and draw attention to the significant impact of obesity on the individuals' personal life with regard to income, in addition to its negative 
impact on socioeconomics. A 4\% increase in healthcare costs corresponds to approximately EUR 136.00 per annum, whereas a $3 \%$ increase in social transfer payments and a $2 \%$ decrease in income correspond to approximately EUR 262.00 and EUR 442.00 per annum, respectively. In other words, the absolute change in income is more than 3 times the absolute change in healthcare costs. This demonstrates that healthcare costs constitute only a minor part of the total costs associated with obesity, based on the absolute numbers. Our results indicate that it is actually the impact of obesity on the labor market that accounts for most of the socioeconomic burden of obesity. Thus, restricting an analysis of the economic impact of obesity to only healthcare costs will lead to underestimation of the actual socioeconomic burden.

Most previous studies have analyzed the relationship between obesity and healthcare costs by comparing different BMI groups, which does not allow a direct comparison of results on healthcare costs. However, our results follow the same pattern as previous findings. The results of the current study that are based on cross-sectional data yet also support findings from longitudinal studies and cohort studies with more follow-ups. Studies have shown increases in both total healthcare expenditures for obese individuals compared to normalweight individuals and increases in subcategories of healthcare costs, e.g. drug costs [10-18, 20-22, 38-43].

Our results in the comorbidity analysis were also in line with previous studies and support our findings in the cost analyses as well. We found that increased BMI was associated with increased comorbidity. This explains the higher social transfer payments, especially costs of social security and disability pension, which points to work disabilities due to the comorbidities of obesity. We identified significantly greater odds for disease code 3: 'blood diseases etc'., code 4: 'endocrine, nutritional and metabolic diseases', code 9: 'diseases of the circulatory system', code 6: 'diseases of the nervous system', and code 19: 'injury, poisoning etc.' per BMI point above 30. Endocrine, nutritional and metabolic diseases and diseases of the circulatory system were the two most common disease groups among obese individuals. Our finding of a higher prevalence of endocrine, nutritional, and metabolic diseases among obese individuals reflects well-known obesity-related diseases such as type 2 diabetes (T2D) $[4-7,44]$, dyslipidemia [5, 7], and polycystic ovarian syndrome [7]. The increase in T2D and dyslipidemia might also partly explain our finding of a $5 \%$ increase in drug costs. Another contribution to the increased drug costs is the increase in diseases of the circulatory system, such as coronary artery disease and hypertension [4-7, 44]. Sleep apnea too is an obesityrelated disease [5, 7], which is included in code 6: 'diseases of the nervous system' and may therefore have contributed to our finding of an increase in this disease group as well. Furthermore, obesity has shown to alter metabolism and interact with age to impair brain function [45], which too may contribute to the increase in code 6. In addition, reverse causality could be part of the explanation; i.e. multiple sclerosis has found to be associated with obesity [46] and epileptic medication to induce weight increase. An interesting finding is the great increase in psychiatric inpatient services (OR 1.10), which does not immediately support the insignificant and close to zero OR of code 5: 'mental and behavioral disorders'. One explanation for this finding may be more hospitalizations per diagnosis, i.e. a schizophrenic patient may be admitted to a psychiatric hospital several times for his disorder but he is not given a new diagnosis for that reason. However, it is not possible to fully explain this association from data. This is the drawback of data from registries: it cannot explain the sometimes illogical associations it identifies.

In the analysis of social transfer payments, we found that the costs of early retirement benefit and child benefit were both negatively affected as they decreased with a rate of $3 \%$ and $1 \%$ per BMI point, respectively. The identified decrease in child benefit is attributable to a decreased birth rate among obese women, as obesity has shown also to be associated with complications in pregnancy and reproductive complications and disorders [7, 47]. The 
decrease in early retirement benefit can be explained by a reduced capacity of work at a younger age than the early retirement age limit. The obese persons are thus assigned other types of social transfer payments, e.g. sick pay and disability pension, as seen in our results.

Our use of the Danish Civil Registration System, which allows for linkage between national registries at the individual level, is a major strength of the study. This data is deemed to be of high quality and is prospectively registered, which makes it less likely to be biased. The estimation of both direct and indirect costs associated with obesity based on this data is what makes the current study unique. The information on height and weight in the Danish National Health Profile is self-reported, which may have resulted in some incorrect measures of BMI. However, if this is the case, these measures have most likely been underestimated, i.e. our findings should be considered conservative estimates. Furthermore, attention should be paid to the fact that the measured indirect costs in this study do not cover all types of indirect costs. For instance, costs due to presenteeism are not included, which too can cause underestimation of the actual estimates. Data on presenteeism is not available but is somewhat included in data on wages, suggesting that underestimation due to lack of data on presenteeism is not of crucial importance. In addition, our results could be suspected of bias because only subjects with BMI $30-50 \mathrm{~kg} / \mathrm{m}^{2}$ were included in the regression analyses. However, an analysis of persons with BMI $25-29 \mathrm{~kg} / \mathrm{m}^{2}$ was conducted but showed no relationship between costs and BMI below BMI 30 for which reason these individuals were excluded as well as the outliers (BMI $>50 \mathrm{~kg} / \mathrm{m}^{2}$ ).

One great shortcoming of this study is that we are not able to prove any causality of obesity and the increased costs. We are only able to identify correlations. This can lead to under- or overestimation of the causal effect if the results on healthcare costs are actually due to an underlying cause. For instance, an underestimation of the causal effect would be the case if obese people were also less likely to make use of healthcare. Conversely, an injury inducing higher healthcare costs and triggering weight increase simultaneously would lead to an overestimation of the causal effect.

\section{Conclusion}

In conclusion, we have found that the increased comorbidity of obesity gives rise to increased direct and indirect costs. Based on national registries, we found a $2 \%$ decrease in income, a 3\% increase in social transfer payments and a $4 \%$ increase in healthcare costs per BMI point above 30. In absolute numbers, the indirect costs constitute the greatest proportion of the total costs associated with obesity, which emphasizes the need for including both direct and indirect costs when evaluating the total socioeconomic burden of obesity. If the prevalence of obesity continues to rise, these costs will increase as well. Our findings emphasize the need to address further the relevance of preventing obesity and thereby save public resources and prevent loss of income. The current study also draws attention to the possibility of reducing public expenses by weight reduction among obese individuals.

\section{Disclosure Statement}

This study was funded by Novo Nordisk, Denmark. 


\section{References}

1 World Health Organization: BMI classification 2017. 2017. http://apps.who.int/bmi/index.jsp?introPage= intro_3.html (last accessed October 5, 2017).

2 Sundhedsstyrelsen: Danskernes sundhed - Den Nationale Sundhedsprofil 2013, Kbh, Kbh., 2014. 125 sider, 2014.

3 Must A, Spadano J, Coakley EH, Field AE, Colditz G, Dietz WH: The disease burden associated with overweight and obesity. JAMA 1999;282:1523-1529.

4 Field AE, Coakley EH, Must A, Spadano JL, Laird N, Dietz WH, Rimm E, Colditz GA: Impact of overweight on the risk of developing common chronic diseases during a 10-year period. Arch Intern Med 2001;161:1581-1586.

5 Haslam DW, James WP: Obesity. Lancet 2005;366:1197-1209.

6 Visscher TL, Seidell JC: The public health impact of obesity. Annu Rev Public Health 2001;22:355-375.

7 Branca F, Nikogosion H, Lobstein T (eds): The Challenge of Obesity in the WHO European Region and the Strategies for Response : EURO Nonserial Publication, 2007.www.euro.who.int/_data/assets/pdf_file/0008/98243/ E89858.pdf (last accessed October 5, 2017).

8 Pi-Sunyer FX: Medical hazards of obesity. Ann Intern Med 1993;119:655-660.

9 Bigaard J, Tjonneland A, Thomsen BL, Overvad K, Heitmann BL, Sorensen TI: Waist circumference, BMI, smoking, and mortality in middle-aged men and women. Obes Res 2003;11:895-903.

10 Finkelstein EA, Fiebelkorn IC, Wang G: State-level estimates of annual medical expenditures attributable to obesity. Obes Res 2004;12:18-24.

11 Colditz GA: Economic costs of obesity. Am J Clin Nutr 1992;55:503S-507S.

12 Colditz GA: Economic costs of obesity and inactivity. Med Sci Sports Exerc 1999;31:S663-667.

13 Katzmarzyk PT, Janssen I: The economic costs associated with physical inactivity and obesity in Canada: an update. Can J Appl Physiol 2004;29:90-115.

14 Levy E, Levy P, Le Pen C, Basdevant A: The economic cost of obesity: the French situation. Int J Obes Relat Metab Disord 1995;19:788-792.

15 Pronk NP, Goodman MJ, O'Connor PJ, Martinson BC: Relationship between modifiable health risks and shortterm health care charges. JAMA 1999;282:2235-2239.

16 Schmid A, Schneider H, Golay A, Keller U: Economic burden of obesity and its comorbidities in Switzerland. Soz Praventivmed 2005;50:87-94.

17 Segal L, Carter R, Zimmet P: The cost of obesity: the Australian perspective. Pharmacoeconomics 1994;5: 45-52.

18 Swinburn B, Ashton T, Gillespie J, Cox B, Menon A, Simmons D, Birkbeck J: Health care costs of obesity in New Zealand. Int J Obes Relat Metab Disord 1997;21:891-896.

19 Thompson D, Edelsberg J, Colditz GA, Bird AP, Oster G: Lifetime health and economic consequences of obesity. Arch Intern Med 1999;159:2177-2183.

20 Tucker LA, Clegg AG: Differences in health care costs and utilization among adults with selected lifestylerelated risk factors. Am J Health Promot 2002;16:225-233.

21 Wolf AM, Colditz GA: Current estimates of the economic cost of obesity in the United States. Obes Res 1998;6: 97-106.

22 Wolf AM, Colditz GA: The cost of obesity: the US perspective. Pharmacoeconomics 1994;5:34-37.

23 von Lengerke T, Krauth C: Economic costs of adult obesity: a review of recent European studies with a focus on subgroup-specific costs. Maturitas 2011;69:220-229.

24 Tremmel M, Gerdtham UG, Nilsson PM, Saha S: Economic burden of obesity: a systematic literature review. Int J Environ Res Public Health 2017;14:pii: E435.

25 Kent S, Fusco F, Gray A, Jebb SA, Cairns BJ, Mihaylova B: Body mass index and healthcare costs: a systematic literature review of individual participant data studies. Obes Rev 2017;18:869-879.

26 Andreyeva T, Sturm R, Ringel JS: Moderate and severe obesity have large differences in health care costs. Obes Res 2004;12:1936-1943.

27 Finkelstein EA, Fiebelkorn IC, Wang G: National medical spending attributable to overweight and obesity: how much, and who's paying?. Health Aff (Millwood) 2003;Suppl Web Exclusives:W3-219-26.

28 Bungum T, Satterwhite M, Jackson AW, Morrow JR Jr: The relationship of body mass index, medical costs, and job absenteeism. Am J Health Behav 2003;27:456-462.

29 Narbro K, Jonsson E, Larsson B, Waaler H, Wedel H, Sjostrom L: Economic consequences of sick-leave and early retirement in obese Swedish women. Int J Obes Relat Metab Disord 1996;20:895-903.

30 Morris S: Body mass index and occupational attainment. J Health Econ 2006;25:347-364.

31 Sarlio-Lahteenkorva S, Lahelma E: The association of body mass index with social and economic disadvantage in women and men. Int J Epidemiol 1999;28:445-449.

32 Trogdon JG, Finkelstein EA, Hylands T, Dellea PS, Kamal-Bahl SJ: Indirect costs of obesity: a review of the current literature. Obes Rev 2008;9:489-500.

33 Neovius K, Johansson K, Kark M, Neovius M: Obesity status and sick leave: a systematic review. Obes Rev 2009; $10: 17-27$

34 DiBonaventura M, Lay AL, Kumar M, Hammer M, Wolden ML: The association between body mass index and health and economic outcomes in the United States. J Occup Environ Med 2015;57:1047-1054.

35 Region Hovedstaden. Forskningscenter for Forebyggelse og Sundhed: Sundhedsprofil. 2017. 
Kjellberg et al.: The Socioeconomic Burden of Obesity

36 The National Board of Health, The National Institute of Public Health, University of Southern Denmark: Danskernes sundhed. Tal fra Den Nationale Sundhedsprofil 2014. 2017.

37 Buntin MB, Zaslavsky AM: Too much ado about two-part models and transformation? Comparing methods of modeling Medicare expenditures. J Health Econ 2004;23:525-542.

38 Thompson D, Brown JB, Nichols GA, Elmer PJ, Oster G: Body mass index and future healthcare costs: a retrospective cohort study. Obes Res 2001;9:210-218.

39 Arterburn DE, Maciejewski ML, Tsevat J: Impact of morbid obesity on medical expenditures in adults. Int J Obes (Lond) 2005;29:334-339.

40 Hojgaard B, Olsen KR, Sogaard J, Sorensen TI, Gyrd-Hansen D: Economic costs of abdominal obesity. Obes Facts 2008;1:146-154.

41 Daviglus ML, Liu K, Yan LL, Pirzada A, Manheim L, Manning W, Garside DB, Wang R, Dyer AR, Greenland P, Stamler J: Relation of body mass index in young adulthood and middle age to Medicare expenditures in older age. JAMA 2004;292:2743-2749.

42 Thompson D, Edelsberg J, Kinsey KL, Oster G: Estimated economic costs of obesity to U.S. business. Am J Health Promot 1998;13:120-127.

43 Wee CC, Phillips RS, Legedza AT, Davis RB, Soukup JR, Colditz GA, Hamel MB: Health care expenditures associated with overweight and obesity among US adults: importance of age and race. Am J Public Health 2005;95: 159-165.

44 Guh DP, Zhang W, Bansback N, Amarsi Z, Birmingham CL, Anis AH: The incidence of co-morbidities related to obesity and overweight: a systematic review and meta-analysis. BMC Public Health 2009;9:88.

45 Bruce-Keller AJ, Keller JN, Morrison CD: Obesity and vulnerability of the CNS. Biochim Biophys Acta 2009; 1792:395-400.

46 Mokry LE, Ross S, Timpson NJ, Sawcer S, Davey Smith G, Richards JB: Obesity and multiple sclerosis: a Mendelian randomization study. PLoS Med 2016;13:e1002053.

47 Broughton DE, Moley KH: Obesity and female infertility: potential mediators of obesity's impact. Fertil Steril 2017;107:840-847. 